\title{
POLA KOMUNIKASI SUAMI ISTRI YANG TIDAK HARMONIS DI GRIYA KENARI KUBANG JAYA SIAK HULU KAMPAR
}

\author{
ERMAIREL SALIM \\ Sekolah Tinggi Ilmu Sosial dan Ilmu Politik Persada Bunda \\ ermairelsalim@gmail.com
}

\begin{abstract}
This research was conducted at the Griya Walnut Village Siak Hulu Riau Kampar Communication entitled Patterns of husband and wife are not Harmonious At Griya Kenari Jaya Siak Hulu Kampar Kubang. This study aims to determine the Communications Patterns husband and wife are not Harmonious At Griya Kenari Jaya Siak Hulu Kampar Kubang. Research benefits expected to be useful both theoretical and practical aspects. Theoretically, this research may be useful for the development of science communication, providing information and contributing communication patterns. Practically, this research is expected to be useful as information for individuals in developing communication patterns husband and wife in a family. In this study used qualitative methods with the intention of digging Communication Patterns of husband and wife are not Harmonious At Griya Kenari Jaya Siak Hulu Kampar Kubang. As for the time of the conduct of this study started from March 2018 to June 2018. Data collection technique is by interview, observation and documentation. Data analysis techniques to the analysis of qualitative data. From the results showed that some family communication patterns that are not in harmony occurs less effective and less fun. This happens because the habit of speaking unfriendly and irritable and grumpy. The habit of talking shout, scold and rage will make married life becomes harmonious. Seoseorang good communication in public, also does not guarantee that a person can communicate well with his family. May talk in front of other people with good communication patterns. As communication patterns by using Hp, too. Often a person communicates with the communication media does not correspond to the truth.
\end{abstract}

Keywords: Communication Patterns, husband and wife and not Harmony.

Abstrak: Penelitian ini dilakukan di Griya Kenari Kelurahan Siak Hulu Kampar Riau berjudul Pola Komunikasi Suami Istri yang Tidak Harmonis Di Griya Kenari Kubang Jaya Siak Hulu Kampar. Penelitian ini bertujuan untuk mengetahui Pola Komunikasi Suami Istri yang Tidak Harmonis Di Griya Kenari Kubang Jaya Siak Hulu Kampar. Manfaat Penelitian diharapkan berguna baik dari aspek teoritis maupun praktis. Secara teoritis, penelitian ini diharapkan dapat berguna untuk pengembangan ilmu komunikasi, memberikan informasi dan memberi sumbangan pola komunikasi. Secara praktis, penelitian ini diharapkan dapat berguna sebagai informasi bagi individu dalam membina pola komunikasi suami istri dalam berkeluarga. Dalam penelitian ini digunakan metode kualitatif dengan maksud menggali Pola Komunikasi Suami Istri yang Tidak Harmonis Di Griya Kenari Kubang Jaya Siak Hulu Kampar. Adapun waktu pelaksanan Penelitian ini dimulai dari bulan Maret 2018 sampai dengan bulan Juni 2018. Teknik Pengumpulan Data yaitu dengan wawancara, observasi dan dokumentasi. Teknik Analisis Data dengan analisis data kualitatif. Dari Hasil penelitian didapatkan bahwa pola komunikasi beberapa keluarga yang tidak harmonis terjadi kurang efektif dan tidak menyenangkan. Hal ini terjadi karena kebiasaan 
berbicara yang tidak ramah dan mudah tersinggung serta pemarah. Kebiasaan berbicara suka membentak, menghardik dan marah-marah akan membuat kehidupan berumah tangga menjadi tidak harmonis. Komunikasi seoseorang yang baik didepan umum juga tidak menjamin seseorang tersebut bisa berkomunikasi baik dengan keluarganya. Bisa saja berbicara di depan orang lain dengan pola komunikasi yang baik. Seperti pola komunikasi dengan menggunakan Hp juga demikian. Seringkali seseorang berkomunikasi dengan media komunikasi tidak sesuai dengan yang sesungguhnya.

Kata Kunci: Pola Komunikasi, Suami Istri dan Tidak Harmonis.

\section{A. Pendahuluan}

Dalam kehidupan manusia di dunia ini tidak dapat dilepaskan dari aktivitas komunikasi, karena komunikasi merupakan bagian penting dari sistem dan tatanan kehidupan sosial manusia dan atau masyarakat. Komunikasi sudah menjadi bagian dari kegiatan seseorang sehari-hari.Jarang disadari bahwa prinsipnya tidak seorang pun dapat melepaskan dirinya dari aktivitas komunikasi. Oleh karena itu komunikasi memegang peranan yang sangat penting dalam kaitannya dengan pembentukan masyarakat.

Banyak pakar menilai bahwa komunikasi adalah kebutuhan yang sangat fundamental bagi seseorang dalam hidup bermasyarakat. Schramm, Wilbur dalam Canggara, Hafied (2012) menyebutkan bahwa komunikasi dan masyarakat adalah dua kata kembar yang tidak dapat dipisahkan satu sama lain. Sebab, tanpa komunikasi tidak dapat masyarakat terbentuk, sebaliknya tanpa masyarakat manusia tidak mungkin dapat mengembangkan komunikasi. Pendek kata, manusia tidak bisa tidak berkomunikasi karena ia adalah makhluk yang dikodratkan untuk hidup berkomunikasi. Dalam keluarga sangat diperlukan komunikasi yang baik antara suami istri serta anak-anak agar tercipta keharmonisan dalam hidup berkeluarga. Pola komunikasi yang baik antara suami istri sangat menentukan keharmonisan dalam berkeluarga. Di Griya Kenari Indah Desa Kubang Jaya Kelurahan Siak Hulu Kampar ada beberapa keluarga yang pola komunikasi suami istrinya tidak harmonis. Hal ini terlihat berdasarkan observasi penulis dan wawancara dengan masyarakat sekitar perumahan tersebut.

Pada beberapa keluarga yang pola komunikasi tidak harmonis ini terlihat sering terjadi pertengkaran antara suami istri, anak-anak sering bertengkar, berteriak histeris, menangis dan menjerit. Para istri juga terlihat begitu tertekan dan kurang bebas bergaul dengan masyarakat sekitar. Pola komunikasi Para suami yang tidak harmonis ini juga terlihat angkuh, sombong, dan kurang bersahabat. Berdasarkan gejala di atas maka peneliti tertarik meneliti "Pola Komunikasi Suami Istri yang Tidak Harmonis Di Griya Kenari Kubang Jaya Siak Hulu Kampar”.

\section{B. Metodologi Penelitian}

Dalam penelitian ini digunakan metode kualitatif dengan maksud menggali Pola Komunikasi Suami Istri yang Tidak Harmonis Di Griya Kenari Kubang Jaya Siak Hulu Kampar. Interpretasi makna tersebut tidak dapat digali melalui verifikasi teori sebagai generalisasi empirik seperti yang dilakukan pada penelitian kuantitatif sehingga pada penelitian ini menggunakan metode kualitatif. Selain itu, penelitian kualitatif bermaksud memahami objeknya dan tidak membuat generalisasi, melainkan membuat eksplorasi atas makna dibalik objek yang telah diteliti. Strauss dan Corbin dalam Nyoto (2015:172) istilah kualitatif dipergunakan untuk penelitian yang tidak 
diperoleh melalui prosedur statistik atau bentuk hitungan lainnya. Penelitian ini bisa berupa penelitian tentang riwayat, kehidupan, perilaku seseorang, peran anorganisasi, pergerakan sosial atau hubungan timbal balik. Tempat Penelitian dilaksanakan Di Griya Kenari Kubang Jaya Siak Hulu Kampar. Adapun waktu pelaksanan ini dimulai dari bulan Maret 2018 sampai dengan bulan Juni 2018. Informan penelitian adalah pihak yang mengetahui atau memberikan informasi maupun kelengkapan mengenai objek. Informan dalam penelitian ini menggunakan informan dimana peneliti sudah memahami informasi awal tentang objek penelitian maupun informan penelitian dengan menggunakan purposive sampling, yaitu teknik pengambilan sampel sumber data dengan pertimbangan tertentu, misalnya orang tersebut dianggap paling tahu tentang apa yang akan diharapkan (Nyoto, 2015:183). Informan penelitian ini berjumlah 15 orang.

\section{Hasil dan Pembahasan}

\section{Komunikasi Primer}

Komunikasi primer merupakan proses penyampaian pikiran oleh komunikator kepada komunikan dengan menggunakan suatu simbol sebagai media atau saluran, dengan adanya komunikasi primer antara pelatih dan atlet maka dapat merpermudah komunikasi dan terjalinnya hubungan yang berjalan dengan baik. Dalam pola ini terbagi menjadi dua lambang yaitu lambang verbal dan lambang non verbal yakni sebagai berikut: a) Lambang verbal yaitu bahasa sebagai lambang verbal adalah yang paling banyak dan paling sering digunakan. Karena bahasa mampu mengungkapkan pikiran komunikator; dan b) Lambang non verbal yaitu lambang yang digunakan dalam berkomunikasi yang bukan bahasa, merupakan isyarat dengan anggota tubuh antara lain mata, kepala, bibir, tangan, dan jari. Selain itu gambar juga sebagai lambang komunikasi non verbal. Sehingga dengan memadukan keduanya maka proses komunikasi dengan pola ini akan lebih efektif. Berdasarkan hasil wawancara dengan responden yang bernama Ersa pada tanggal 20 Maret 2018: "Komunikasi yang terjadi di rumah tangga kami sering hanya satu arah saja karena saya lebih banyak diam ketika suami saya berbicara. Saya malas berbicara karena takut suami saya marah jika saya salah berbicara atau tidak sesuai dengan keinginannya. Biasanya jika saya tidak mengiyakan apa yang dia katakana, dia akan marah dengan melempar berbagai peralatan kepada saya. Bahkan sampai main tangan jika kita tidak cepat menuruti apa yang dia suruh. Daripada ribut dan malu didengar tetangga, diam adalah lebih baik".

Berdasarkan hasil observasi penulis, di keluarga Ersa mereka hidup hanya berdua suami istri karena belum memiliki anak/keturunan. Mereka menikah sudah cukup lama lebih dari 10 tahun. Ersa bekerja di instansi swasta dan juga memiliki usaha sampingan. Suami Ersa menurut informasi tetangga yang tidak begitu jelas dimana dan apa pekerjaannya. Suami Ersa juga biasanya pulang pagi hampir di setiap harinya, sore hari baru keluar rumah lagi. Pola Komunikasi yang terjadi di Keluarga Pipit juga kurang harmonis dan efektif, berdasarkan hasil wawancara penulis dengan Pipit 25 Maret 2018: "Suami saya suka egois dalam berbicara dialah yang benar segalanya, dia sekarang tidak/kurang menghargai saya dalam berkomunikasi. Dulu awal-awal menikah dia menghargai, sopan berbicara pada saya. Setelah begitu lama berumah tangga itu mulai berkurang, lebih-lebih lagi sekarang saya sudah tidak bekerja lagi dan hanya mengurus anak dirumah". Berdasarkan hasil observasi penulis, didapatkan informasi dari para tetangga Pipit bahwa Pipit dulunya bekerja sebagai guru kontrak 
SMK (Sekolah Menengah Kejuruan). Sekarang sudah jadi Ibu rumah tangga saja. Suami Pipit bekerja sebagai Marketing di salah satu Bank swasta Pekanbaru.

Pola komunikasi yang terjadi di keluarga Binong berbeda dengan keluarga Ersa dan Pipit. Suami Binong bekerja di luar kota dan hanya sesekali pulang jika lebaran atau ada keperluan saja. Sebagaimana hasil wawancara penulis dengan Binong: "Suami saya jarang pulang, dia bekerja di Palembang dan kalau pulang hanya sesekali saja, dulu sering pulang, sekarang sudah agak jarang. Biasanya jika dia pulang, seperti raja saja. Apa yang diminta dan diinginkannya harus cepat tersedia, jika tidak dia akan marah dan membentak-bentak sama anak-anak. Saya kadang merasa tertekan jika dia berada dirumah".

Berdasarkan hasil wawancara penulis dengan tetangga Binong, Ersa dan Pipit yang bernama Surahmi Tanggal 5 April 2018 mengatakan: "Kami jarang sekali berkomunikasi dengan suaminya Binong karena dia jarang pulang dan kelihatannya pendiam saja. Jika suami Ersa jarang berkumpul dengan Bapak-Bapak disini, kalau dia berkomunikasi dengan kita sepertinya agak sombong dan suka meninggikan diri jika berbicara. Suami Pipit lebih tertutup, jarang berbicara dengan kita. Jika berjumpa dia hanya melihat saja tanpa tersenyum kepada kita. Kadang, ada berjumpa di warung sewaktu dia membeli rokok. Dapat disimpulkan bahwa pola komunikasi beberapa keluarga yang tidak harmonis di atas terjadi kurang efektif dan tidak menyenangkan. Hal ini terjadi karena kebiasaan berbicara yang tidak ramah dan mudah tersinggung serta pemarah. Kebiasaan berbicara suka membentak, menghardik dan marah-marah akan membuat kehidupan berumah tangga menjadi tidak harmonis.

\section{Komunikasi Sekunder}

Pola komunikasi secara sekunder adalah proses penyampaian pesan oleh seseorang kepada orang lain dengan menggunakan alat atau sarana sebagai media kedua setelah memakai lambang sebagai media pertama. Berdasarkan hasil wawancara penulis dengan Bapak Adi warga Griya Kenari Tanggal 7 April 2018mengatakan: "Saya melihat orang-orang yang pola komunikasinya kurang baik itu dimulai dari rumah dimana dia dibesarkan dan bagaimana pendidikan dasar dikeluarganya. Jika didalam keluarga dibiasakan berbicara tidak baik, kebiasaan ini akan terbiasa sampai dia besar bahkan sudah menjadi kebiasaan sehari-hari”.

Berdasarkan hasil observasi penulis terlihat bahwa orang-orang yang memiliki pola komunikasi yang kurang baik kurang menyenangkan dalam pergaulan. Para suami pada keluarga yang tidak harmonis di atas pada umumya tidak menyenangkan didalam pergaulan. Semakin sering kita berkomunikasi dengan baik dengan orang lain, akan membuat kepribadiaan kita menjadi baik.

Berdasarkan hasil wawancara penulis dengan Ami Tanggal 20 April 2018 warga Griya Kenari mengatakan: "Saya kurang suka melihat suaminya Ersa jika berbicara karena suka menyombongkan diri dan merasa lebih hebat terus, padahal kami tau dia itu siapa. Yang kami lihat dia selalu berbicara kasar kepada istrinya Ersa padahal istrinya seorang yang cukup disegani dan memiliki profesi menurut kami sangat bagus. Tapi kami lihat suaminya selalu berkata kasar dan menyuruh istrinya dengan nada tidak menghargai sama sekali. Hal ini membuat kami yang kurang respect terhadap suaminya, seperti orang hebat saja, kami lebih menghargai Ersa jika berbicara dengan nada sopan, lembut walaupun agak sedikit tertutup".

Pola komunikasi sekunder juga bisa terjadi melalui alat komunikasi Hand Phone/ Hp. Hampir semua orang mulai dari anak-anak, remaja, dewasa dan orang tua bisa menggunakannya. Berdasarkan hasil wawancara penulis dengan Ibu Wina warga Griya E-ISSN: 2657-0300 Lembaga Penelitian dan Penerbitan Hasil Penelitian Ensiklopedia 353 
Kenari Tanggal 23 April 2018 mengatakan: "Saya lihat suaminya Pipit pendiam dengan kita-kita, wajahnya seperti orang baik-baik, tapi ampun, saya tak sanggup dengar kata-katanya kalau dia memarahi istrinya. Apalagi jika menyuruh istrinya suka berteriak-teriak, tiada kelembutan sedikitpun. Yang anehnya jika dia berbicara dengan orang lain seperti orang baik-baik dan tidak pemarah serta kasar. Jika menelpon atau menjawab telpon dari seseorang sepertinya dia orang ramah dan baik. Padahal sebenarnya seorang yang kasar dan ketus, mungkin dia pura-pura baik pada orang lain, menyembunyikan sikapnya yang tidak baik. Itulah sebabnya kami malas berbicara dengan suaminya Pipit, takut dibentak seperti perlakuan pada istrinya. Mungkin itu juga sebabnya istrinya tambah kurus, makan hati sepertinya".

Komunikasi seoseorang yang baik didepan umum juga tidak menjamin seseorang tersebut bisa berkomunikasi baik dengan keluarganya. Bisa saja berbicara di depan orang lain dengan pola komunikasi yang baik. Seperti pola komunikasi dengan menggunakan Hp juga demikian. Seringkali seseorang berkomunikasi dengan media komunikasi tidak sesuai dengan yang sesungguhnya.

\section{Penutup}

Berdasarkan pembahasan pada Bab sebelumnya di atas, maka penulis dapat menarik kesimpulan bahwa pola komunikasi yang tidak baik akan menimbulkan ketidakharmonisan dalam keluarga, tetangga dan orang lain. Pola komunikasi yang tidak baik membuat orang lain malas/takut berkomunikasi dengan kita. Melalui penelitian ini dan berdasarkan kesimpulan di atas, maka dianjurkan kepada kepala rumah tangga berkomunikasilah dengan baik karena laki-laki adalah panutan/pemimpin dalam keluarga. Jika kita menghargai orang lain dalam berkomunikasi, kita akan disenangi banyak.

\section{Daftar Pustaka}

Basrowi dan Suwandi. 2008. Memahami Penelitian Kualitatif. Jakarta: Rineka Cipta Cangara, Hafied. 2012. Pengantar Ilmu Komunikasi. Jakarta: Rajawali Pers,

Deddy, Mulyana. 2008. Metodologi Penelitian Kuantitatif. Bandung: PT Remaja Rosda karya

Dewi, Sutrisna. 2007. Komunikasi Bisnis. Yogyakarta: ANDI

Efendy, OnongUchjana. 2010. Ilmu Komunikasi Teori dan Praktek. Bandung: Remaja Rosda Karya

Elvinaro Ardianto dan Bambang Q-Anees. 2009. Filsafat Ilmu Komunikasi. Bandung: PT. Remaja Rosdakarya.

Emzir. 2012. Metodologi Penelitian Kualitatif, Analisis Data. Jakarta: Rajawali Pers Enjang, AS. 2009. Komunikasi Konseling. Bandung: Nuansa

Moleong, Lexy J. 2008. Metodologi Penelitian Kualitatif. Bandung: Remaja Rosda Karya

Nyoto.2015. Metodoligi Penelitian Teori dan Aplikasi. Pekanbaru: UU Pers

Purwanto, Djoko. 2011. Komunikasi Bisnis. Jakarta: Erlangga

Riswandi. 2009. Ilmu Komunikasi. Yogyakarta: Graha Ilmu

Rosmawaty. 2010. Mengenal Ilmu Komunikasi. Bandung: Widya Padjadjaran.

Ruliana, Poppy. 2014. Komunikasi Organisasi Teori dan Studi Kasus. Jakarta: Rajawali Pers 
Stewart L. Tubss dan Sylvia Moss. 2008. Human Communication Perinsip-perinsip Dasar. Bandung: PT. Rosda Karya

Sugiyono. 2012. Memahami Penelitian Kualitatif. Bandung: Alfabeta

Sukadiyanto.2014. Pengantar Teori dan Metodologi Melatih Fisik. Yogyakarta: FIK UNY

Supratiknya. 2008. Tinjauan Psikologis Komunikasi Antarpribadi. Yogyakarta: Kanisius

Suranto, AW. 2011. Komunikasi Innterpersonal. Yogyakarta: Graha Ilmu

Wiryanto. 2008. Pengantar Ilmu Komunikasi. Jakarta: Grasindo

Zuriah, Nurul. 2009. Metodologi Penelitian Sosial dan Pendidikan. Jakarta: Bumi Aksara

http://www.irmanfsp.com/2015/08/pola-pola-komunikasi.html?m=1 (20 Juli 2018) 